\title{
Organización comunitaria y turismo en dos comunidades del estado de Hidalgo, México
}

\author{
Cristina Flores Amador* \\ Facultad de Turismo y Gastronomía \\ Universidad Autónoma del Estado de México \\ Lilia Zizumbo Villarreal \\ Graciela Cruz Jiménez \\ Centro de Investigación y Estudios Turísticos \\ de la Facultad de Turismo y Gastronomía \\ Universidad Autónoma del Estado de México
}

\section{Resumen}

En este artículo se sostiene que la economía social es una alternativa de organización en el contexto campesino mexicano, que favorece el desarrollo local en las comunidades rurales mediante la implementación de grupos de trabajo, cooperativas y asociaciones. En este sentido, la incorporación del turismo en el medio rural está permitiendo a sus poblaciones transformar sus recursos naturales en servicios turísticos, contribuyendo a emprendimientos desde la economía social. Con base en la teoría de la economía social, se estudian dos comunidades indígenas del estado de Hidalgo: El Palmar y El Alberto, donde destaca la participación colectiva en actividades turísticas y proyectos endógenos bajo esquemas de organización y producción solidaria. Desde un enfoque cualitativo, la información recopilada posibilitó demostrar que la organización colectiva de los pobladores en el aprovechamiento de sus recursos naturales para el turismo ha propiciado modificar su situación de pobreza, mejorar sus expectativas de vida y, sobre todo, garantizar la reproducción social de la vida. Se concluye que, establecido desde la economía social, el turismo en las comunidades rurales fortalece el sentido comunitario en el medio rural indígena.

\section{Palabras clave}

Economía social, turismo rural, desarrollo local, El Palmar y El Alberto, México.

Recibido: 03/11/2014 · Aceptado: 09/05/2015

*Correo electrónico: cristinafloresamador@hotmail.com·1zv04@yahoo.com · gracicj@hotmail.com 


\title{
Communal organization and tourism in two communities of the State of Hidalgo, Mexico
}

\author{
Cristina Flores Amador* \\ Facultad de Turismo y Gastronomía \\ Universidad Autónoma del Estado de México \\ Lilia Zizumbo Villarreal \\ Graciela Cruz Jiménez \\ Centro de Investigación y Estudios Turísticos \\ de la Facultad de Turismo y Gastronomía \\ Universidad Autónoma del Estado de México
}

\begin{abstract}
In this article it is proposed that social economy is an organizational alternative in the Mexican peasant context that favors local development in rural communities through the implementation of work groups, cooperatives and associations. In this sense, the inclusion of tourism in the rural environment allows people to transform their natural resources into tourism services thus contributing to entrepreneurial initiatives based on social economy. On the basis of social economy theory, two indigenous communities of the state of Hidalgo are studied: El Palmar and El Alberto where collective participation in tourism activities and endogenous projects under organizational and productive collaboration are highlighted. Under a qualitative approach, the collected information demonstrates that the collective organization of the community members in the use of their natural resources for tourism purposes is conductive to the modification of their poverty situation, to increasing their life expectancy and above all, to guarantee the social reproduction of livelihoods. It is concluded that tourism, established within the framework of social economy in rural communities strengthens communal identity in the rural indigenous context.
\end{abstract}

\section{KEY WORDS}

Social Economy, rural tourism, local development, El Palmar and El Alberto, Mexico.

*E-mail: cristinafloresamador@hotmail.com·lzv04@yahoo.com·gracicj@hotmail.com 


\section{Introducción}

En los últimos años, el medio rural mexicano ha enfrentado un panorama de abandono, sobre todo en la actividad agrícola, cuyo papel en cuanto dinámica productiva y económica se ha visto significativamente afectada, modificando el modelo campesino predominante de las zonas rurales, que han perdido su valor como base de supervivencia en el tejido socioeconómico, debido a la escasa fertilidad de las tierras, a servicios inadecuados, infraestructura deficiente, migración de los jóvenes a otros países, envejecimiento de la población e inseguridad derivada de la delincuencia, a lo que se suman las escasas esperanzas de mejoramiento; esto ha agravado la situación del mundo rural, acentuado la pobreza y dado pie a la perdida de interés y arraigo territorial.

Ante esta situación de crisis han surgido alternativas de desarrollo local -entre ellas el turismo rural sustentado en la economía social-, mediante formas organizativas endógenas, en las que emergen estructuras de participación de los actores locales. Estos emprenden experiencias e iniciativas colectivas sobre el uso y aprovechamiento de sus recursos naturales y culturales, convirtiéndolos en productos y servicios turísticos que les sirven para atender sus necesidades más apremiantes, pues, valiéndose del turismo y de la economía social, generan fuentes de riqueza y trabajo. Así, como reconoce Rico González (2005), gracias a sus atractivos turísticos, han impulsado incipientes servicios, como alojamiento rural, actividades lúdico-medioambientales y comercio de productos artesanales dirigidos al turismo.

Esta estrategia de desarrollo en el campo incluye nuevas funciones y responsabilidades desde lo comunitario, pues al buscar formas diferentes de fortalecer las capacidades de las personas la organización del trabajo da lugar a un sistema capaz de proporcionar fuerza efectiva a proyectos colectivos en una sociedad más igualitaria, más justa y autodeterminada, partiendo de la asociación, el trabajo comunitario y la producción simple de mercancías en emprendimientos individuales, familiares o cooperativos y de las redes de coalición (Coraggio, 2003: 154).

Apoyándose en este enfoque, las comunidades rurales buscan crear para sí empleos estables, recurriendo a la especialización de trabajos y a la prestación de servicios turísticos -que ofrecen a partir de sus condiciones territoriales, sociales, económicas, políticas y culturales-, lo cual posibilita la acumulación de 
un excedente sobre el que idealmente tienen un completo control, tanto de la generación de la riqueza como de su distribución (Molina, 1998: 165). Además, como señala Coraggio (2003), cuentan con la participación voluntaria y los procedimientos democráticos de toma de decisiones bajo procesos asociativos de aprendizaje y mejora continua, basados en la confianza, la reciprocidad y la solidaridad. Las formas de organización comunitaria establecidas entre los integrantes de la población del medio rural dinamizan el tejido socioeconómico, el arraigo y la identidad, la conservación de sus recursos naturales y la protección ambiental, al tiempo que, a partir de la actividad turística, fortalecen la cohesión social.

Este es el caso de El Palmar y El Alberto, dos comunidades rurales mexicanas asentadas en el valle del Mezquital en el estado de Hidalgo, que tienen en común ser indígenas -pertenecientes a la familia otomí-pame- y haber establecido durante los últimos años un sistema productivo y una forma de vida colectiva a partir de la oferta y prestación de servicios turísticos, que se han constituido en su actividad económica predominante. Tal proceso lo han realizado gracias a una organización regida por la confianza, la solidaridad y la reciprocidad, elementos básicos de la economía social.

La afluencia turística en estos lugares se debe a su importante y particular riqueza natural y cultural, así como a las transformaciones y puesta en práctica de actividades innovadoras que integran a su entorno físico y social, creando más opciones de recreación para los visitantes y obteniendo mayores beneficios económicos y bienestar para sus comunidades. Estas se encuentran apartadas del mundo moderno, y desde hace décadas han sufrido los efectos de la exclusión, la falta de apoyo y el deterioro de sus fuentes de trabajo. Lo anterior los decidió a aprovechar sus recursos naturales y sus tierras -ofreciendo servicios turísticos-, organizándose según los principios de la economía social, lo que les ha permitido aminorar sus condiciones de marginación y no seguir dependiendo de la asistencia conferida por la política social o de la cada vez más exigua producción agrícola.

Su estrategia primordial fue sustituir la insuficiencia de tierras productivas con la promoción de servicios y bienes que complementan el turismo rural. Cada comunidad ha conseguido opciones favorables que atienden las necesidades de su población, enfrentando los embates de la política neoliberal fomentada en el 
país durante los últimos años. En este sentido, las dinámicas socioeconómicas y políticas introducidas en El Palmar y El Alberto han fortalecido la conformación de esquemas de trabajo y de distribución equitativa, lo que ha tenido notables resultados en sus procesos de organización económica, social y política. Teniendo en cuenta lo anterior, la investigación aquí reportada tuvo como objetivo: analizar la economía social -en cuanto alternativa de organización en el contexto campesino-, la cual favorece el desarrollo en las comunidades rurales mediante el establecimiento de grupos de trabajo, cooperativas y asociaciones constituidos a partir de su incorporación al turismo.

La investigación titulada "Turismo rural como factor de desarrollo local, desde la perspectiva de la comunalidad en una comunidad rural. El Alberto, estado de Hidalgo" se fundamenta en la propuesta teórica de la economía social, y toma como ejes de análisis no solo las formas de organización sino también las de producción, distribución y consumo, sustentadas, como ya se dijo, en la confianza, la reciprocidad y la solidaridad comunitarias. El presente artículo tiene como marco metodológico el modelo teórico para abordar el turismo rural planteado por Flores et al. (2014), el cual, desde la economía social, pretende aportar un esquema lógico para analizar la actividad turística en su calidad de estrategia para avanzar hacia el desarrollo local en un área rural, mediante una perspectiva dinámica, productiva y de participación voluntaria, regida por acciones autogestivas dentro del tejido social comunitario, las cuales determinan los componentes del modo de vida, la condición de subsistencia, así como la transformación equitativa de organización y cohesión social en las comunidades estudiadas.

\section{El turismo rural desde la economía social}

Las zonas rurales han dejado de considerarse espacios destinados exclusivamente a sostener la producción agrícola; hoy en día, algunas de ellas son concebidas como áreas multifuncionales donde de forma simultánea pueden realizarse distintas actividades, de ahí que la producción alimenticia solo sea una entre varias y que la prestación de servicios para el ocio, la recreación y el turismo generen mayores expectativas (Capristo, 2006). En tales espacios se enfatizan sus capacidades para resistir los embates neoliberales, convirtiendo 
sus recursos naturales y culturales en productos y servicios turísticos, para, a partir de ellos, crear una oferta innovadora que desde el enfoque de la economía social sea viable comercializar a través del turismo rural. En consecuencia, este turismo puede ubicarse como una posibilidad de empleo rural no agrícola (Mollinedo, 2008), pues se perfila como una vía natural para el desarrollo de las zonas rurales, en especial de las más desfavorecidas, explotando los recursos del agro no solo como materia prima para la industria, sino también como factor de atracción para los visitantes (Vogel et al., 2004).

Esta propuesta es particularmente útil en las comunidades que, basándose en la economía social y en el trabajo solidario, luchan a ultranza por mantenerse independientes de los programas y planes socioeconómicos fomentados por las instituciones del Estado; de ese modo conservan el control comunitario incluyente en las decisiones tomadas (sobre una base colectiva) acerca de la propiedad de las tierras, de la naturaleza de tal propiedad y de los medios de producción. Por tal razón, el turismo rural es considerado una alternativa de desarrollo que: a) puede generar empleo para los campesinos en su propia comunidad, b) diversifica la oferta turística, $c$ ) contribuye a la conservación del patrimonio natural y cultural de las regiones desfavorecidas económicamente, $d$ ) otorga valor a los recursos locales que se encuentran en manos de productores, en su mayoría en áreas ejidales, organizados en cooperativas o asociaciones comunales (Garduño, Guzmán y Zizumbo, 2009). Estos autores plantean, asimismo, que tener la opción de ofrecer un servicio turístico detonando las potencialidades de la comunidad les abre la puerta para activar la economía local redistribuyendo los ingresos y beneficios producidos, lo que democratiza su economía y se convierte en un mecanismo de inclusión y diversificación de actores de la economía social, que funciona como eje generador del desarrollo, concebido este como la expansión o realización de potencialidades e implicaciones para mejorar la calidad de vida (Cruz, 2008).

Ante este panorama, el turismo rural abre amplias perspectivas para innovar y catapultar el capital social comunitario, entendido como "el conjunto de conocimientos colectivos, prácticas, técnicas productivas y formas de cooperación ancestrales que generan eficiencia económica y que han asegurado la supervivencia 
secular de un grupo social” (Maldonado, 2005: 4). A partir de la instauración del turismo rural, las comunidades rurales, principalmente indígenas, han procurado incorporar la economía social como una forma de organización comunitaria de la actividad turística -buscando nuevas modalidades de integración de los individuos al trabajo- y, con ello, abatir las condiciones de pobreza y exclusión en las que han vivido durante años (Zizumbo Villarreal, 2007: 250-252).

El turismo rural organizado con base en la economía social tiene la posibilidad de crear estructuras más eficaces y eficientes para la reproducción de la vida desde una acción colectiva suficientemente fuerte y orientada por un paradigma de desarrollo humano. En este sentido, y como consecuencia de lo expuesto por Coraggio (2009), puede proponerse que el impulso de un proyecto alternativo de desarrollo es capaz de construir una economía social centrada en el trabajo como recurso principal -mas no el único-, donde la lógica no es acumular el capital dinero ni el capital político, sino el capital humano (Coraggio, 2003). De ahí que sea admisible argumentar que esto les confiere el carácter endógeno que distingue a la autosuficiencia socioeconómica (Monterroso y Zizumbo, 2008). Entonces, una de las ventajas de abordar el turismo rural a partir de la economía social y del propósito de contribuir con el desarrollo local es mostrar que existen alternativas económicas que, gracias a esfuerzos comunitarios, permiten hacer frente al neoliberalismo, en especial para las comunidades que buscan la autosuficiencia económica recurriendo a opciones que impulsan, desde las propias zonas rurales, un enfoque más amplio para mejorar su vida. Esto, tras constituir emprendimientos individuales y colectivos con nuevas formas de incorporación al trabajo, que reviertan las condiciones de pobreza y exclusión, de modo que esté a su alcance enfrentar problemas que interfieran en su organización, por una parte, y defenderse de la política y cultura dominantes, por la otra.

Para abundar en el funcionamiento de la economía social en proyectos de turismo rural, en el siguiente apartado se hace una referencia más detallada a las dos comunidades aquí estudiadas, las cuales han llevado a cabo proyectos de este tipo. 


\section{El Palmar: construcción de una organización comunitaria alternativa}

El Palmar es una comunidad indígena de la etnia hñähñú-otomí, ubicada en el valle de El Mezquital, en el estado de Hidalgo. Su fecha de fundación es imprecisa; sin embargo, los pobladores creen que fue establecida a mediados del siglo xv. Hacia 1917, año en que se constituyó como ejido, contaba con 1900 hectáreas de régimen ejidal y comunal. En 1978, por conflictos territoriales y diferencias políticas, el área fue dividida y compartida con la comunidad de Santiago de Anaya, municipio al que pertenece en la actualidad. Por decreto gubernamental, a los pobladores de El Palmar solo les corresponden 1020 hectáreas de régimen comunal; para el usufructo de estas tierras, sus pobladores se distribuyeron y organizaron para legalizar el total de los terrenos, que dividieron en parcelas, dando posesión para su uso individual; se acordó que cada jefe de familia las cultivaría y conservaría, y se conformó la asamblea general de comuneros, estructura organizativa por medio de la cual determinaron que esa tierra no se podía vender ni negociar, pues todos tendrían derecho a ella. Asimismo, establecieron que solo los oriundos de la comunidad podían usarla, por lo que estaba prohibido cederla a personas ajenas a la población. A partir de entonces, el trabajo y la administración se rigen por las decisiones convenidas en la asamblea general.

La comunidad El Palmar se distingue por estar en una zona árida con clima semidesértico: muy caliente por el día y con bajas temperaturas por la noche; cuenta con tierras poco fértiles, por lo que la producción de cultivos siempre ha sido reducida. También, debido al clima e insuficiente infraestructura agrícola se ha caracterizado por tener un territorio pobre y escasamente productivo, a lo que se suma la falta de apoyos gubernamentales y su grado de marginación. Aunque está próxima a la cuenca del río Moctezuma, no tiene ríos ni lagunas, así que para el consumo humano utiliza el agua de las presas cercanas: La Salitrera y Pejay (Pérez Aguilar, 2008).

En el siglo pasado esto no era así; la comunidad tenía un sistema de riego que utilizaba aguas residuales para abastecer a la población local y a las zonas aledañas, lo cual generaba problemas de salud pública, pero permitía la producción para autoconsumo. Anteriormente se cultivaba maíz y frijol con la esperanza de obtener cosechas con que alimentar a la familia; no obstante, 
la producción era insuficiente, por lo que decidieron aprovechar la flora de la región, compuesta por plantas xerófilas: como maguey, mezquites, nopal y distintos agaves, que han formado parte de los productos de uso local y para su venta en otras poblaciones. Hoy en día, en las tierras más secas se cosecha maguey, tuna, nopal y xoconostle, cultivos que no necesitan grandes cantidades de agua, y que comercializan y transforman en artesanías de ixtle (derivado del maguey) para tener ingresos y apoyar su economía (Fox y Rivera, 2005: 68-69). Entre otras actividades económicas, practicaban la cacería de pequeñas especies de la zona: conejo, liebre, zorro, ardilla, víbora de cascabel y lagartija, e insectos como escamoles, gusanos de maguey y chinicuiles, que eran y continúan siendo parte de su dieta, pero ahora además las aprovechan vendiéndolas en los pueblos cercanos; de igual modo, se apoyaban en el negocio adicional de recolección de leña. Todo esto no alcanzaba a cubrir las necesidades mínimas y por ello algunos jefes de familia se empleaban como jornaleros o albañiles, y las mujeres en trabajos domésticos, de manera señalada en Ixmiquilpan y en Pachuca (capital del estado).

De acuerdo con el último censo, El Palmar tenía 823 habitantes (430 hombres y 393 mujeres) (Sedesol, 2010b); 246 son menores de edad y 577 adultos; del total, 588 viven en hogares indígenas. La población está conformada por un grupo social con alto grado de cohesión. De la comunidad, 95 \% habla el idioma hñähñú. El Palmar tiene 180 hogares, de los cuales 150 tienen instalaciones sanitarias; 176 viviendas cuentan con luz eléctrica. En materia educativa destaca que $8.74 \%$ de la población de 15 años o más es analfabeta, $2.53 \%$ de los niños de 6 a 14 años no asiste a la escuela, y $52.46 \%$ de las personas de 15 años y más no completó la educación básica. En cuanto a la salud, $19.60 \%$ de sus habitantes carece del servicio, pues no es derechohabiente de las instituciones del sector salud (Sedesol, 2010a). Lo anterior pone de manifiesto que los servicios no son los más adecuados para cubrir algunas necesidades básicas de salud, educación, seguridad y bienestar, dado que existen carencias de infraestructura que no permiten transformar la calidad de vida. Las condiciones de las viviendas revelan que $1.52 \%$ de los pobladores habita casas con piso de tierra, $56.06 \%$ no tiene lavadora y $18.94 \%$ no posee refrigerador (Sedesol, 2010a).

En razón de lo anterior, el índice de rezago social de la comunidad es $-0.969051 \%$, lo que ubica a El Palmar en un alto grado de rezago social (Sedesol, 2010a). El deterioro de la economía campesina, sumado a las malas cosechas 
y a la baja producción, provocó la migración, sobre todo de los hombres jefes de familia e hijos mayores de edad. En un principio migraban hacia la Ciudad de México, lo que ocasionó la separación de los campesinos respecto de sus medios de producción y su ubicación en un mercado de trabajo asalariado. Posteriormente viajaron de forma ilegal a Estado Unidos, donde se empleaban en labores domésticas, agrícolas y en aquellas que les dieran ingresos suficientes para enviar dinero a sus familias en El Palmar; en consecuencia, la población predominante en la comunidad se redujo a mujeres y niños, por lo que también disminuyó la fecundidad (2.83 hijos por mujer) (Sedesol, 2010b). Poco a poco las familias de migrantes comenzaron a mejorar su economía e iniciaron actividades comerciales dentro de la comunidad, entre ellas la elaboración de artesanías, venta de comida y oferta de servicios; esto último en especial a partir de los años ochenta, cuando comenzaron a llegar grupos de visitantes a la comunidad atraídos por su riqueza natural, en particular por las grutas de Xoxafi (que significa trueno).

No obstante, durante muchos años la comunidad vivió excluida y marginada de los apoyos institucionales; sus peticiones y requerimientos solo eran atendidos de manera clientelar y conforme a la conveniencia de los gobiernos en turno. La política agraria no los consideró sujetos productivos porque estaban ubicados en áreas poco fértiles, de mal temporal y, sobre todo, de propiedad comunal. Solo les dirigieron políticas de beneficencia social, esporádicas y condicionadas, que resultaban denigrantes y nulas para su desarrollo; por lo tanto, decidieron mantenerse -como hasta la fecha- alejados de los organismos y dependencias gubernamentales federales, estatales o locales; pues más que ayudarlos, los debilitaban, marginaban y quebrantaban su identidad y colectividad.

En la década de 1980 la población empezó a recibir viajeros atraídos por las grutas de Xoxafi, emblemáticas del lugar y de amplio interés para quienes practican la espeleología. Se trata de una manifestación natural de gran belleza, que permite experimentar el auténtico ecoturismo y la aventura. Es una montaña del valle de El Mezquital que, por accidente geológico, hace millones de años se perforó en varios túneles, quedando una enorme caverna donde se aprecian pinturas rupestres; esto motivó a los pobladores a prestar servicios turísticos. Al principio ofertaban visitas guiadas para que los turistas conocieran las cavernas y, simultáneamente, se gestaba una forma de organización comunitaria 
colectiva basada en la economía social, a partir del trabajo organizado y la distribución igualitaria de los beneficios, lo que empezó a cambiar los críticos escenarios que padecía la comunidad El Palmar.

La organización colectiva posibilitó aprovechar la riqueza natural que estaba siendo demandada por los paseantes. Los pobladores proporcionaban un ambiente natural inigualable en los recorridos en el interior de las grutas, y los visitantes disfrutaban de deportes extremos, gastronomía y otras actividades, como el espectáculo anual de la Sinfónica del Estado de Hidalgo, que se presenta en abril en un espacio acondicionado de la gruta principal; este acto artístico se ha convertido en una genuina atracción, así como otros servicios turísticos en sus valles, cuyo éxito ha radicado en la forma en que estructuraron la organización comunitaria del trabajo turístico.

Años después, en los noventa, los propios ejidatarios continuaron investigando y explorando las grutas y encontraron dos rutas más profundas y más estrechas, pero viables para guiar a los excursionistas; esto amplió la oferta comercial, promoviendo paseos organizados y la práctica de rapel, tirolesa y campismo. A partir de esta oportunidad, que los propios pobladores crearon, se fue generando un proceso de descampesinización, pues un cada vez mayor número de habitantes se incorporaba a trabajar y a capacitarse para prestar servicios recreativos en las tierras de la comunidad, contando con la participación de todos los integrantes de cada familia.

Para ello, se establecieron reglas según las cuales todos están obligados a cumplir con las faenas y a dar las cooperaciones que se establezcan para limpieza, mantenimiento, seguridad, ampliaciones y construcción, lo cual provocó que se comenzara a tener confianza y certeza de que a partir del turismo la comunidad podría transformar su vida y fortalecer la solidaridad y equidad entre la población; es así que consideraron trascendental el turismo, y lo adoptaron como su forma de trabajo y de vida.

En la actualidad, los trabajadores turísticos oscilan entre 75 y 92 ejidatarios propietarios de tierras $;{ }^{1}$ conformaron la empresa denominada Desarrollo Turístico Grutas de Xoxafi, bajo el régimen de sociedad de producción rural de responsabilidad ilimitada (como quedó estipulado en su acta constitutiva). Cabe señalar que 15 ejidatarios se encuentran en Estados Unidos o no se interesaron

${ }^{1}$ Trabajo de campo (noviembre de 2014). 
en participar y solo reciben una cuota simbólica de renta, según los acuerdos emitidos por el grupo de ejidatarios. La empresa está conformada por una asamblea general y un consejo de administración. Cuando se toman decisiones asisten los representantes de cada familia y los habitantes en general. Fidel Hernández es el presidente y Armando Rodríguez el secretario, por un periodo de dos años, y tienen posibilidad de reelegirse. La asamblea general de comuneros determinó la asignación interna de actividades individuales y colectivas, conforme a las necesidades y resultados obtenidos.

Los cambios más significativos en la comunidad se presentaron, no obstante, después de la construcción, en el año 2000, de la carretera que une a El Palmar con el acceso a Santiago de Anaya y a Ixmiquilpan, lo que mejoró las condiciones de la zona y propició contar con vías de acceso seguras y adecuadas. Además, los pobladores iniciaron tareas que favorecían el lugar: enmallado de los terrenos y zonas turísticas, delimitación para optimizar los espacios, colocación de palapas, asadores, construcción de escalinatas para las grutas, edificación de un restaurante y locales comerciales, así como seis cabañas, todo ello con mano de obra de los ejidatarios y materiales de la región. Las ganancias obtenidas del turismo fueron reinvertidas, lo que estimuló el aumento de la corriente turística nacional, en especial de la Ciudad de México, del Estado de México, de las ciudades de Querétaro y Guadalajara y del propio estado de Hidalgo, sobre todo para la celebración de Semana Santa y las vacaciones de verano y decembrinas. A partir de 2004 empezó el arribo de turismo extranjero, en particular espeleólogos y estudiosos de los murciélagos y de la biodiversidad del lugar, provenientes de Estados Unidos, Canadá, Alemania y Francia.

En El Palmar, la actividad turística ha mantenido un equilibrio entre la oferta y la demanda en los servicios, uso y aprovechamiento de los recursos naturales y culturales; esto ha sido posible gracias a la distribución de actividades y organización social creada a través de la economía social, donde los actores locales participan de manera voluntaria, activa y comprometida, responsabilizándose solidariamente de sus tareas individuales y colectivas, lo que favorece la estructura gubernamental, económica y sociocultural. La comunidad colabora de conformidad con sus usos y costumbres, guiada por principios de igualdad, dinamizando el tejido socioeconómico, el arraigo y la identidad; al tiempo en que se ocupa de la protección ambiental y del fortalecimiento de las formas de producción y distribución. 
Cabe señalar que aunque la gente continúa cosechando algunos alimentos para autoconsumo, estos son pocos. Por ende, la base de las unidades familiares para mejorar sus condiciones de vida es la organización del trabajo para el turismo. A pesar de las condiciones de exclusión y sometimiento predominantes causadas por el sistema capitalista, que continua penetrando en las comunidades, El Palmar es la muestra de cómo una comunidad rural campesina, que se desarrolla con base en la organización del trabajo, puede mantener relaciones comunitarias y una producción sustentada en el trabajo familiar, que persigue como objetivo la reproducción, el equilibrio y el interés por una situación de mayor seguridad y desarrollo local desde el turismo.

\section{El Alberto: la organización del trabajo turístico}

La comunidad rural indígena El Alberto está ubicada en la parte desértica del valle de El Mezquital en el estado de Hidalgo, en el centro de una cadena montañosa, donde sobresale un cañón natural. Durante la época colonial, fue nombrada Santa Cruz Alberto y formaba parte de los 16 pueblos pertenecientes a la jurisdicción de Ixmiquilpan; a diferencia de otras, no vivió intensos procesos de mestizaje y logró conservar la pureza de su población, sobre todo en cuanto a su lengua e identidad.

Esta comunidad ya existía antes de la Conquista y, según documentos del Archivo General de la Nación, fue de las primeras en la zona en hacerles frente a los españoles. Se extiende en 1600 hectáreas de propiedad comunal (Pérez Aguilar, 2008). En 1989 la reforma agraria adjudicó legalmente 1135 hectáreas, 20 áreas y 71 centiáreas de agostadero cerril a 247 comuneros de El Alberto (Gobierno del Estado de Hidalgo, 1989, cit. en Serrano Avilés, 2006: 67-74). A finales de los ochenta se distribuyeron las tierras de riego y a cada comunero le correspondió un poco más de una hectárea; por consiguiente, en la actualidad los jefes de familia de este pueblo tienen una superficie agrícola de riego bastante limitada, casi nula, para trabajar. Según el Padrón de Usuarios de la Comisión Nacional del Agua del Estado de Hidalgo, las tierras de riego de El Alberto abarcan 351 hectáreas. Su población asciende a 834 habitantes (397 hombres y 437 mujeres), la mayoría son bilingües otomí-español (Sedesol, 2010b). 
La comunidad mantiene un sistema ancestral de gobierno que ha facilitado la preservación y continuidad de un proyecto político de identidad étnica en un contexto de comunidades mestizas (Álvarez, 2006). Este sistema se mantiene por la intervención colaborativa y la división jerárquica política, civil y religiosa (católica y evangélica), a través de la rotación periódica de cargos para la toma y ejecución de decisiones.

La población registra un alto grado de marginación con -0.3196, y su índice de rezago social es de -0.222877 (Conapo, 2010), cifras que revelan la difícil situación socioeconómica que afrontan sus habitantes, y que inhibe sus posibilidades de mejorar las condiciones de vida de las familias y de la comunidad. La población de 15 años y más analfabeta asciende a $35.32 \%$, y el porcentaje de personas con educación básica incompleta es de 68.09\% (Sedesol, 2010a). Además, aunque en las 217 viviendas de la comunidad se registra un porcentaje mediano en la cobertura de servicios públicos, $9.68 \%$ habita en casas con piso de tierra, lo que aumenta el riesgo de padecimientos respiratorios, oftalmológicos y alérgicos. Además, un alto porcentaje de viviendas (22.48\%) no dispone de drenaje, $12.58 \%$ no cuenta con sanitario -lo que genera problemas de contaminación que exponen a la gente a potenciales enfermedades e infecciones-, y $1.84 \%$ no tiene agua entubada ni energía eléctrica. El nivel de hacinamiento es de $21.77 \%$. Sobre la disponibilidad de bienes, destaca que $70.5 \%$ no tiene lavadora, $6.73 \%$ carece de refrigerador y $42.5 \%$ no posee televisión (Sedesol, 2010a). La población derechohabiente del seguro popular asciende a 396 personas (Sedesol, 2010a).

A mediados de los años ochenta se calcula que cerca de $30.11 \%$ de los hogares contaba con al menos un migrante internacional circular o un migrante de retorno, con fines laborales. De esos hogares, 29.15 \% recibía remesas (Tuirán, 2000). Años después, $23.81 \%$ contaba con al menos un migrante internacional y $23.1 \%$ cobraba remesas producto de trabajos en la construcción, ayudantes, empleos domésticos y servicios, sobre todo en Cleveland, Los Ángeles, Nevada y Las Vegas (Gómez, 2000). Puesto que 98 \% de los migrantes son hombres en edad fértil (Sedesol, 2010b) las tasas de crecimiento y de fecundidad han disminuido (Lozano, 2002).

En lo concerniente al turismo, durante el año 2000 se observó un aumento significativo del flujo de personas, promovido especialmente por aquellos que ya habían visitado la comunidad. Esto dio lugar a la organización de la comunidad para ofrecer servicios turísticos, los cuales comenzaron a brindarse de 
forma empírica y rudimentaria, a partir de una actitud colaborativa. Los primeros servicios brindados fueron alimentos, área para acampar; después lanchas para pasear en el río Tula y apreciar "el Gran Cañón”, así como escalar en las formaciones rocosas del lugar. Todo esto incentivó la llegada de más turismo.

La organización comunitaria para la oferta de servicios turísticos estimuló a los ejidatarios a constituirse legalmente como cooperativa ejidal y crearon la Sociedad de Solidaridad Social EcoAlberto, que tiene reconocimiento formal ante las dependencias gubernamentales municipales, estatales y federales. Fue una iniciativa de 80 ejidatarios, quienes llevaron a cabo las gestiones formales externas e internas. ${ }^{2}$ Así, se impulsó la organización del trabajo, se mejoró la infraestructura y se diseñaron las actividades turísticas, lo que incrementó y diversificó la afluencia de visitantes, que ahora vienen de otros estados del país y del extranjero.

A pesar de estos cambios, la comunidad no ha dejado de contar con una organización ancestral guiada por los usos y costumbres, cuya máxima autoridad es la asamblea general comunitaria, donde se toman las decisiones y en forma abierta se define la voluntad comunal. Está conformada por subcomités de 15 a 20 integrantes; los representantes de la asamblea general y la población se rigen de acuerdo con su identidad étnica y territorial y conservan mecanismos de control otorgando cargos o tequio, que todos los miembros de las comunidad (residan en ella o hayan migrado) están obligados a cumplir (Rivera-Salgado, 1999; Velasco, 1999: 132-133).

El Alberto ha conseguido conformar dos unidades productivas: la unidad gerencial básica de servicios turísticos y una empresa de agua, que constituyen la Sociedad de Solidaridad Social Eco-Alberto, administrada como una empresa social comunitaria. En este sentido, la incorporación de los pobladores de esta comunidad al trabajo turístico no ha afectado sus costumbres, estilo de vida ni identidad, lo cual significa que continúan siendo un grupo rural indígena, cuya economía y proyecto de organización colectiva está encaminado hacia la mejora de la subsistencia local. Los comuneros de El Alberto perciben en el turismo una práctica muy importante, en la que todos sus habitantes se involucran prestando servicios, y consideran que $80 \%$ de su vida depende del turismo y de sus actividades complementarias. ${ }^{3}$

2 Ídem.

${ }^{3}$ Ídem. 
El éxito de esta sociedad se debe a la capacidad de organización y mecanismos estructurales de trabajo definidos con apego a su territorio y régimen gubernamental, apoyados en la identidad cultural y religiosa (usos y costumbres), que a su vez se basan en redes de reciprocidad, solidaridad, justicia, cooperativismo y confianza. El turismo se lleva a cabo de manera principal alrededor de los recursos naturales, en especial del agua, que proporciona condiciones para realizar un sinfín de actividades (aguas termales, río, albercas, recorridos por el río Tula) y permite el disfrute de los turistas, que además pueden practicar deportes y actividades recreativas, así como una caminata nocturna, en la que con la participación activa de los asistentes se aborda la historia de los migrantes.

\section{Propuesta teórico-metodológica para abordar la economía social}

El eje analítico para examinar si la organización comunitaria del turismo rural ha favorecido el desarrollo local en El Palmar y El Alberto fue la propuesta teórica de la economía social conceptuada como:

espacio de acción social constituido no por individuos utilitaristas buscando ventajas materiales, sino por individuos, familias, comunidades y colectivos de diverso tipo que se mueven dentro de instituciones decantadas por la práctica o acordadas como arreglos voluntarios. [Estos actores realizan] transacciones entre la utilidad material y valores de solidaridad y de cooperación, limitando (no necesariamente anulando) la competencia [Coraggio, 2003].

Se recurre a esta teoría para investigar un caso empírico en el que se implementa este tipo de economía, basada en lo social, pues se producen relaciones constituidas en la confianza, el respeto y la solidaridad; concibiendo valores de uso para satisfacer las necesidades de los mismos productores, con sus peculiaridades socioproductivas y culturales; sin tener como propósito final únicamente la obtención de utilidades económicas o la acumulación sin límites. Además,

el sector de economía social no se orienta a la sustitución de un sistema capitalista liberal; tampoco se concibe como subproducto de la evolución cíclica del capitalismo, sino que emerge como una [...] institución más del sistema económico, diferente al sector público y del sector capitalista y tan estructural como ellos, forzosa 
para mejorar la asignación de recursos y la redistribución de la renta, consolidando la estabilización económica necesaria por un crecimiento equilibrado y sostenido, respetuoso del sistema ecológico rural [Monzón, 1998].

La economía social conforma una realidad inmersa en un determinado sistema socioeconómico global y no constituye “otra economía” independiente; por ello, no debe estudiarse de forma aislada, sino desde una configuración integral, multidisciplinaria y dinámica, dada la evolución y las condiciones en las que se adaptan las exigencias del entorno. Así, la economía social implica una forma innovadora de producción, reproducción, distribución y acción colectiva, que constituye: "un sistema de relaciones económicas y sociales que posibilitan, en un marco de solidaridad y de reciprocidad, la conformación de diversas formas de organización para la producción económica y comunitaria” (Feigelman, 2008). En este contexto, la economía social se considera una estrategia al interior de los procesos de desarrollo local, que posibilita el desarrollo de los territorios y la generación de ingresos, pero también de alternativas productivas para amplios sectores sociales, no solo para los sectores populares (Altschuler y Casalis, 2006). Bajo este enfoque, la economía social involucra un conjunto de experiencias asociativas que producen bienes y servicios, en las cuales no se prioriza el lucro, más bien se valoriza el trabajo, la satisfacción de necesidades por parte de sus integrantes, la solidaridad entre productores, trabajadores y con otros grupos asociativos, en el marco de una sustentabilidad ampliada de emprendimientos, que contempla aspectos sociales, económicos, ambientales y culturales.

Su objetivo es generar trabajo y responder a necesidades concretas de la sociedad, en particular de los sectores excluidos y en situación de vulnerabilidad. Es por ello que la economía social tiene diferentes connotaciones y actualmente es utilizada como una base que impulsa el desarrollo desde lo social, enfatizando que este desarrollo es para el beneficio de las comunidades, las poblaciones locales y las familias (Coraggio, 2002). En concordancia con estos planteamientos, la propuesta investigativa que respalda este artículo se fundamenta en los siguientes elementos básicos de la economía social (que ponen de relieve la vida comunal y sus estructuras organizativas), planteados por Coraggio (2011, 385-389), a quien nos permitimos citar in extenso. 
Elementos relativos a la producción

a) Trabajo para todos. El trabajo digno es condición de la reproducción y desarrollo de la vida humana. Todo grupo o comunidad debe tener la posibilidad de integrarse voluntariamente al sistema de división social del trabajo en condiciones que permitan el desarrollo de sus capacidades, en especial el trabajo asociativo autogestionado, solidario y autónomo de poderes.

b) Acceso de los trabajadores a todas las formas de conocimiento. Para convertirse en la principal fuerza productiva, el trabajo autónomo de patrones requiere incorporar las diversas formas de conocimiento.

c) Acceso de los trabajadores a medios de producción. Implica la defensa de condiciones previas de producción y de vida, así como la redistribución de tierras.

d) Cooperación solidaria. Es la forma de integración social del sistema de producción. La competencia está subordinada a este principio, evitando las formas violentas que amenazan la convivencia pacífica. Se favorecen formas de complementariedad productiva.

e) Autogestión colectiva de las condiciones de la producción y la reproducción. Más allá de los procesos productivos particulares, implica la propiedad/control y gestión colectiva de infraestructuras.

f) Producción socialmente responsable. Se refiere al cuidado de la calidad de los productos para la satisfacción de las necesidades de los consumidores, además de los efectos de producción sobre el medio ambiente.

Elementos relativos a la distribución y redistribución

a) Justicia social, garantía de la reproducción y desarrollo de la vida de todos. Inserción económica de los excluidos de la economía, particularmente de los más pobres, de modo que puedan resolver sus necesidades a partir de su propio trabajo o de la solidaridad democrática.

b) A cada poblador según su necesidad y su trabajo. Evitar diferencias fuertes entre trabajadores. 
c) No explotación del trabajo ajeno. No se admiten formas de esclavitud, dependencia forzada por la violencia física, ni la apropiación del producto del trabajo ajeno.

d) Redistribución. Apropiación y distribución colectiva del excedente dentro de cada unidad económica, apropiación y redistribución por una autoridad central legítima, procurando la justicia social.

\section{Elementos relativos a la circulación}

a) Autosuficiencia (autarquía). Se propicia el desarrollo de la capacidad de cada comunidad por satisfacer con seguridad lo necesario con sus recursos, principalmente el propio trabajo. La ubicación especializada dentro del sistema de división social del trabajo y comercio se subordina al principio de autosuficiencia y seguridad a nivel comunitario.

b) Reciprocidad. Relaciones simétricas (cooperativas, redes de trueque y ayuda mutua para seguridad social).

c) Intercambio. Privilegio del comercio justo, regulación gradual del mercado como mecanismo de coordinación de iniciativas, protección de actividades locales por métodos culturales, sociales y políticos, reducción de costos de intermediación.

\section{Elementos relativos al consumo}

a) Consumo responsable. Este último elemento se refiere a consumir lo suficiente en equilibrio con la naturaleza, sobre la base de solidaridad, justicia, e igualdad, orientadas por el paradigma del "buen vivir o el vivir bien”.

Los elementos enunciados, tomados literalmente de (Coraggio, 2011), sirvieron como base para diseñar y aplicar los siguientes instrumentos de investigación: guía de observación, que permitió identificar el contexto geográfico, social, de producción, turístico, económico y gubernamental, y la guía de entrevista a profundidad, que facilitó obtener información directa, apreciaciones actuales y pasadas de informantes clave como el comisariado ejidal y de bienes comunales, representantes de la asamblea, pobladores en general y aquellos que intervienen en la prestación de servicios turísticos. Lo anterior aportó 
elementos para profundizar sobre los beneficios y los efectos del turismo en las dos comunidades rurales estudiadas, y se llegó a los siguientes resultados.

\section{Resultados}

En ambas comunidades la prestación de servicios turísticos desde la economía social a partir de sus formas de organización ha fortalecido las prácticas cotidianas de los ámbitos económico, social, político, cultural y religioso; esto puede verse tanto en la forma colectiva de realizar la producción, la distribución y la circulación, como en los beneficios que se manifiestan en el consumo mediante el reparto de los recursos generados.

En cuanto a la producción, son los comuneros quienes deciden cómo administrar sus recursos; hombres y mujeres deben realizar actividades y desempeñar diversas labores con base en los fines propuestos, lo cual favorece que todas las personas incluidas intervengan en la decisión colectiva sobre el rumbo que debe tomar la producción solidaria y la planificación socialmente responsable. La autogestión colectiva democrática permite alcanzar las ventajas de una verdadera autonomía económica. Además, la autogestión es posible gracias a que los trabajadores participantes son propietarios de los medios de producción. De este modo, en ambas comunidades la producción de bienes y servicios, incluyendo los turísticos, tiene como objetivo contribuir a mejorar la calidad de vida de todos. Uno de los principales beneficios al crear sus propias actividades y diseñar su oferta es la generación de empleos. Se busca que estos sean ocupados por la población local y que generen igualdad de oportunidades entre todos los habitantes; asimismo repercuten en los servicios de interés y uso general, relacionados con la oferta de servicios turísticos.

En consecuencia, es posible argumentar que, por medio de la producción, en El Alberto y en El Palmar se han dado efectos favorables y otros potenciales sobre la cohesión territorial, ya que sus habitantes se organizan en actividades económicas enfocadas al mantenimiento del espacio rural. Asimismo, en estas comunidades rurales, la creación de empleos se apoya en aspectos como fomentar la decisión colectiva de mantener la residencia en esta zona, así como la estabilidad y la calidad del empleo, que promueven el crecimiento y la certeza laboral. 
Por otra parte, es posible destacar que las dos poblaciones se caracterizan por la prestación de bienes y servicios turísticos basados en los recursos naturales y culturales que les identifican. Además, la producción se construye con la participación de sus habitantes, que organizan actividades recreativas y la venta de productos artesanales, utilizando el trabajo como el factor que hegemoniza y vigila los medios de producción, la oferta y las formas de organización, pues son los miembros de la comunidad quienes controlan las decisiones. A lo anterior hay que agregar que la riqueza natural y cultural que integra sus bienes y servicios es protegida y cuidada bajo la administración de los pobladores, que son conscientes de la importancia de continuar favoreciéndose de ella, al utilizarla como base de la oferta turística.

La distribución y redistribución son indispensables para el avance estratégico de la organización a partir de la economía social, pues hombres y mujeres despliegan un sentimiento de ayuda mutua y cooperación; para esto, no basta un poco de solidaridad al modo convencional, se requiere que esta solidaridad sea tan fuerte y central que reestructure el modo de hacer las cosas. Por consiguiente, en ambas comunidades la igualdad de oportunidades está más presente en su día a día, pues, para lograr un verdadero desarrollo social, su organización es incluyente y se guía por los lineamientos internos de respeto, reciprocidad y solidaridad.

En estas poblaciones existe coincidencia sobre la distribución de los ingresos y beneficios tangibles e intangibles que utilizan de forma comunal para satisfacer de manera equilibrada los intereses de todos los actores; priorizan las relaciones de igualdad, y así concilian una mejor vida familiar y local.

De igual forma, a partir de la cooperación y la inclusión, los pobladores de El Alberto y El Palmar favorecen la cooperación colectiva por encima del interés individual, a fin de garantizar la participación y la justicia social entre los habitantes en las actividades y en el reparto de los recursos y utilidades. Por consecuencia, desarrollan la actividad turística sin necesidad de intermediarios o apoyos externos, y distribuyen equitativamente y en pequeñas cantidades los beneficios y capital que generan. Este mecanismo refuerza la confianza entre la población y fortalece los lazos que garantizan la mecánica respecto del uso de las ganancias que perciben.

En asamblea general se acordó que las ganancias se reinviertan para mantener, mejorar y ampliar las instalaciones. En este contexto, para optimizar los 
escenarios cotidianos y futuros, los pobladores asumen una actitud de no explotación o discriminación en el trabajo, y al mismo tiempo existe transparencia en la organización y en la distribución de recursos, bienes y servicios. Además, las comunidades emplean estrategias para distribuir las funciones y actividades cotidianas y las de índoles turística, recurriendo a criterios consensuados, de forma justa y equilibrada. La variedad de trabajos y de necesidades se atiende con la participación de los hombres, distribuyendo cargos y creando canales de comunicación e intervención equitativa.

Los dividendos económicos, las responsabilidades, el reconocimiento y la colaboración se distribuyen dependiendo de las condiciones existentes y los propósitos planteados. Según esta idea, el control sobre la distribución de los bienes y de las áreas turísticas está a cargo solo de los pobladores, con la disposición de transformar y acondicionar sus espacios para brindar mejor atención al turista. No se admite la intervención de agentes externos en estas localidades, con la firme determinación de no involucrar intereses que pudieran dañar su paz y tranquilidad.

El proceso de la circulación tiene como función que los bienes y servicios lleguen a los consumidores. Se concreta a través de técnicas de intercambio, de redes de reciprocidad y solidaridad armónica -por sobre la ayuda generosa- y de la promoción de formas de comercio y términos de intercambio justos; es decir, a partir de la relación entre productor y consumidor y entre un productor y otro, con el objetivo de satisfacer las necesidades de la población. Tan es así, que los comuneros de El Alberto y El Palmar ponen en práctica la racionalidad económica, es decir, procuran la búsqueda y circulación del excedente en cada unidad económica, con el propósito de asegurar mejores condiciones de vida para la reproducción material y espiritual de sus familias. También, persiguen la reproducción del tejido social, por lo cual el excedente económico no es un fin en sí mismo, si no un medio necesario para la reproducción social. Viven con sus propios recursos, en particular del trabajo, dentro de su propio sistema de división social del trabajo y del turismo, esforzándose por conseguir en su comunidad la autosuficiencia, la seguridad y la soberanía. Los pobladores conciben la circulación como la reproducción de la vida, no como la acumulación de capital; por esa razón son determinantes los principios y valores que 
caracterizan a estas comunidades. Igualmente, en la comunidad existen relaciones simétricas, a partir de redes de ayuda mutua, para la seguridad social y apoyos solidarios, de hecho, de manera esporádica practican el trueque, lo que fortalece la unión y la circulación de intercambio, contribuyendo a salvaguardar su cultura. Además emplean mecanismos de coordinación democrática e iniciativas vinculadas al ingreso económico y a las relaciones que regulan las actividades locales; con ello se preserva un ambiente de responsabilidad para propiciar la reducción de costos e inversión innecesaria, velando por los intereses colectivos, a partir de la idea de que el turismo genera ingresos y dinero para reforzar el tejido social local -el dinero es un medio y no un fin-.

En este marco, el turismo ha propiciado beneficios y seguridad respecto de la circulación, por medio de la reciprocidad entre la comunidad y la búsqueda de una circulación próspera y de certeza. Por otra parte, para aportar soluciones y preservar la colectividad a través del turismo, se mantiene un diálogo permanente con una minoría de los habitantes que tienen discrepancias.

El consumo responsable se expresa con la utilización de los bienes y servicios por parte de los habitantes para satisfacer sus necesidades. El consumo es de dos clases: el individual y el colectivo de producción. En las dos comunidades el consumo individual cubre las necesidades vitales de las personas; mientras que el productivo se refiere al uso del patrimonio y medios de creación para ofertar servicios y bienes turísticos planificados por la propia comunidad; con ello atienden sus requerimientos primordiales y además pueden reinvertir.

Al igual que otros procesos económicos, sociales y políticos, en El Alberto y El Palmar existe un modelo enfocado al bienestar colectivo; su dinámica de consumo se condiciona socialmente por tres motivos: 1) por proceso de no acumulación, 2) por la estructura de distribución económica y 3) mediante acciones convenidas para su desarrollo cultural. En estas acciones el consumo se divide equitativa, organizada y responsablemente; en primer término satisfacen sus obligaciones familiares e individuales, aprovechando con responsabilidad sus recursos; posteriormente atienden las necesidades de la actividad turística para garantizar el uso óptimo de bienes de consumo y así lograr mayor bienestar. De hecho, los pobladores manifiestan que aun cuando tuvieran un nivel de consumo más elevado ello no les aseguraría un grado superior de felicidad individual ni colectiva. 
Han conseguido afianzar y practicar de forma homogénea el hábito del consumo responsable, derivado de un proceso de sensibilización e información en cuanto a los beneficios que resultan de su rol en el trabajo turístico, en casa o individual. Así, buscan un equilibrio colectivo en el que no tratan de anular la individualidad de las personas, sino complementarla gracias a la cooperación y la acción grupal.

\section{A manera de conclusiones}

Una vez expuestos los procesos de cambio qua han vivido las comunidades estudiadas y analizadas sus condiciones socioeconómicas, culturales y turísticas, es posible concluir que la organización comunitaria en torno al turismo rural desde la economía social ha favorecido el desarrollo local en las comunidades indígenas El Palmar y El Alberto, en el estado de Hidalgo. Lo anterior ha sido posible porque esta actividad productiva se ha implementado desde la economía social, teniendo en cuenta las formas de organización, producción, distribución y consumo, sustentadas en la confianza, la reciprocidad y la solidaridad comunitarias.

La estructura organizativa alcanzada demuestra que han avanzado hacia el desarrollo local en sus comunidades gracias al sistema, estructuras y práctica de actividades endógenas colectivas, y que, por medio de la economía social, han creado e impulsado el aprovechamiento y la transformación de sus recursos naturales y culturales en bienes y productos para la prestación de servicios turísticos; además de haberse constituido como empresas comunitarias y sociedades cooperativas, solidarias y responsables sustentadas en el trabajo de sus miembros.

A partir de esa dinámica organizativa, la conversión de los pobladores de campesinos, empleados, jornaleros y migrantes en prestadores de servicios turísticos y trabajadores comunitarios permitió modificar favorablemente su vida. Por ende, a pesar de seguir siendo grupos rurales cuya economía está dirigida hacia la subsistencia, han podido integrarse al mercado ofertando servicios turísticos con base en formas de organización colectiva, en las que prevalece la confianza y la reciprocidad, y diversificando fuentes de trabajo. Estas acciones les proporcionan un contexto de vida individual y familiar más ventajoso. No son 
grandes empresarios, pero han instaurado medios de producción y distribución equitativa, en los que participan voluntariamente, para mejorar sus condiciones, por lo que actualmente enfrentan un panorama de bienestar socioeconómico, y político más propicio. Han modificado sus circunstancias de vida, fortalecido e incrementado sus redes de ayuda mutua y de cooperación, con base en la división, control y garantías igualitarias de beneficios y responsabilidades.

Es así que, en las dos comunidades, son significativos y trascendentes los efectos derivados de su organización apoyada en los elementos de la economía social, pues han conseguido que la población continúe viviendo en su territorio, sin la necesidad de buscar empleo en otro país. De igual modo, han podido conservar la propiedad de su tierra, con lo cual mantienen el control; a la vez, ellos mismos atienden sus fuentes de trabajo, dando continuidad a su identidad y costumbres, y proporcionando mayor certeza para sus hijos y generaciones futuras.

En este contexto, el turismo ha registrado una evolución paulatina y generado impactos positivos, entre otros la organización de la comunidad acorde con el crecimiento de la demanda turística y el aumento en la oferta de servicios. Hasta 2004, el turismo en El Alberto se registraba solo en Semana Santa y días feriados, pero últimamente ha tenido un incremento considerable durante todo el año, debido a que incorporó la caminata nocturna, en la cual sus habitantes recrean las vivencias de los migrantes al llegar ilegalmente a Estados Unidos. Tal producto ha tenido gran éxito entre los visitantes nacionales y extranjeros, debido al atractivo y peculiaridad del recorrido.

Por su parte, en 2005, en dos rutas de El Palmar se integró al programa de actividades recreativas la tirolesa, y han sido relevantes los conciertos de diferentes orquestas sinfónicas en el interior de las grutas de Xoxafi -el principal atractivo de esta comunidad-. Tales modificaciones aumentaron la afluencia y los ingresos, pero también la necesidad de que todos los habitantes participaran en atender a los turistas. Asimismo, ambos lugares han tenido mayor promoción en medios electrónicos dirigidos a segmentos de mercado regional, estatal, nacional e internacional. En la actualidad la población de El Alberto manifiesta que el turismo es una práctica muy importante, en la que todos participan prestando servicios turísticos, seguridad, construcción o en cualquier labor asociada que se les encomiende. En tal virtud, consideran que su vida depende en $80 \%$ del 
turismo y de sus actividades complementarias, además de que han conseguido empleo digno y seguro.

Por su parte, los pobladores de El Palmar mencionan que $90 \%$ de sus habitantes participa en las labores asignadas en asamblea relativas al turismo, del que manifiestan depender en $80 \% .{ }^{4}$ Entonces, el avance y el éxito experimentados por las dos comunidades es resultado de la capacidad estructural de cada grupo organizado y del aprovechamiento endógeno de su patrimonio natural e identidad cultural, que se manifiesta en sus redes de solidaridad, cooperativismo y confianza; ello ha fortalecido la cohesión social y posibilitado encauzarse hacia el desarrollo local.

Lo anterior, gracias a una estructura económica y de gobierno basada en lo social, donde los actores cumplen un rol fundamental en su ejecución, fortalecimiento y difusión, a partir de su realidad, historia y riqueza cultural, generando valores de usos y costumbres para cubrir las necesidades de los habitantes, con sus propias características productivas. Esto es así porque sus formas de producción y circulación se orientan a satisfacer sus necesidades, más que a obtener ganancias.

Debe destacarse que en El Alberto y en El Palmar sí se practican los elementos de la economía social orientados a las actividades y servicios turísticos, puesto que el territorio y sus recursos son un factor común de los pobladores, que les permiten forjar identidad, adhesión y confianza, generando arraigo. Además, a través de sus medios de producción, y modos de organización e integración, mantienen fortalecidos los ámbitos social, administrativo y de control; es así que el uso turístico de los recursos naturales de ambas comunidades ha significado transformaciones para disponer de ellos. A su vez, el trabajo por medio del sistema de cargos sin remuneración económica funciona, y facilita la ejecución de las decisiones que toma la asamblea general, que es el máximo órgano de autoridad. De este modo es como respaldan y sustentan los acuerdos formulados bajo esquemas de equidad y respeto en la producción, distribución y consumo responsable de los bienes, servicios y beneficios generados por el turismo. Esto se conduce en todo momento por principios de reciprocidad y solidaridad, de manera voluntaria y comprometida, ya que comparten idénticos intereses y propósitos, manteniendo unidad y colectividad.

${ }^{4}$ Ídem. 
En consecuencia, en un marco de sólida estructura en la economía social, El Alberto y El Palmar han avanzado hacia el desarrollo local con cambios radicales en los escenarios de pobreza que les aquejaban, y ponen de manifiesto nuevas formas de intervención que no dependen de organizaciones gubernamentales, y, además, llevan a la práctica una alternativa al sistema capitalista -con iniciativas creativas de organización y actividades cooperativas de consumo y producción, por medio del trabajo articulado para gestionar los recursos y necesidades de cada uno de los miembros y de la comunidad en general, orientadas al bienestar social, innovando, ahorrando, e invirtiendo con equidad.

Con los argumentos formulados se establece que el turismo rural implementado en El Alberto y El Palmar y el adecuado uso de sus recursos naturales y culturales representan una opción de desarrollo para las poblaciones rurales, porque les ayuda a contrarrestar los efectos negativos del proceso de globalización y del sistema capitalista que identifica al actual periodo de neoliberalismo.

\section{Futuras investigaciones}

La investigación que respalda este artículo tiene la intención de contribuir a futuros estudios que se sustenten en la teoría de la economía social. Para ello es necesario que tengan en cuenta los elementos básicos que hacen viable una experiencia de éxito, como la de las dos comunidades rurales analizadas, que se transformaron de campesinas a prestadoras de servicios turísticos, motivadas por el apremio de modificar y mejorar sus condiciones de desamparo, aprovechando su entorno geográfico y atractivos naturales para ofertarlos turísticamente. Por lo tanto, son un ejemplo de superación, que recurriendo a su organización endógena, participación solidaria y estructura de reproducción social basada en la colectividad responsable y compartida, promovida por la confianza y la justicia social, paulatinamente están logrando el desarrollo local.

Con un enfoque metodológico basado en la economía social, bajo una dimensión moral -y no de acuerdo con una visión neoliberal- y con una orientación que analiza las necesidades sociales y la mejora de la calidad de vida en esas poblaciones, los resultados expresados en este documento buscan informar de lo ocurrido en dos comunidades rurales que, articulando los intereses colectivos, han sido capaces de solucionar sus problemas sociales, económicos 
y políticos internos, por encima de aquellos donde intervienen actores, organismos y dependencias externas, lo cual les ha permitido afirmar la articulación de los intereses colectivos.

En consecuencia, es importante reconocer que es posible fortalecer los componentes de la economía social, cuya base es el trabajo por un objetivo en común, y no solo la suma de todos los esfuerzos. Pero reforzar sus elementos lleva tiempo, requiere voluntad, compromiso y colaboración integral.

El turismo rural puede ser una estrategia de desarrollo local en cuanto proceso territorial, humano, sistémico, sustentable y participativo, para reducir la pobreza y mejorar las condiciones de vida en las comunidades rurales. Para ello, es indispensable la intervención armónica y exhaustiva de los actores locales, a fin de transitar hacia la consecución de propósitos comunes. De igual forma, es preciso dar continuidad al análisis de procesos de desarrollo, a partir del esfuerzo y del compromiso que propicien el aprovechamiento de la actividad turística sustentada en la economía social.

\section{Fuentes citadas}

Altschuler, B. y A. Casalis (2006). "Aportes del desarrollo local y la economía social a una estrategia de desarrollo", en D. García Delgado y L. Nosseto (comps.). El desarrollo en un contexto posneoliberal. Hacia una sociedad para todos. Buenos Aires: Centro de Integración, Comunicación, Cultura y Sociedad-Facultad Latinoamericana de Ciencias Sociales, 71-118.

Álvarez, J. (2006) "La emigración internacional en el estado de Hidalgo”, en P. Vargas (coord.). Hidalgo. Población y Sociedad al siglo XXI. Pachuca: Centro de Estudios de Población-Universidad Autónoma del Estado de Hidalgo, 243-264.

Conapo (2010). Índice de marginación por localidad 2010 [en línea]. Consejo Nacional de Población. Disponible en: http://www.conapo. gob.mx/work/models/CONAPO/indices_margina/2010/documentoprincipal/Capitulo01.pdf [2015, 19 de febrero].

Coraggio, J.L. (2002). "La economía social como vía para otro desarrollo social”, presentado en el debate "Distintas Propuestas de 
Economía Social”, Red de Políticas Sociales Urbanas (Urbared), Biblioteca Virtual тор sobre Gestión Pública [en línea]. Disponible en: www.top.org.ar/publicac.htm

------ (2003). La política social y economía del trabajo. Zinacantepec: Miño y Dávila/El Colegio Mexiquense.

(2009). “Territorio y economías alternativas”. Ponencia presentada en el I Seminario Internacional Planificación Regional para el Desarrollo Nacional. Visiones, desafíos y propuestas, La Paz, Bolivia, 30-31 de julio.

------ (2011) Economía social y solidaria. El trabajo antes que el capital., en A. Acosta y E. Martínez (eds.). Flacso/Abya Yala, Quito, 385-389

Cruz, G. (2008). “Ecoturismo y turismo sustentable”. El Periplo Sustentable, 3 (28), 5-30.

Feigelman, D. (2008). “Del Plan de Inclusión Social al Plan de Integración Económica”. Revista oIDLES [en línea], 2 (4). Disponible en: http://www.eumed.net/rev/oidles/04/df.htm

Flores, C. et al. (2014). "Turismo rural como factor de desarrollo local, desde la perspectiva de la comunalidad en una comunidad rural. El Alberto, Estado de Hidalgo". Revista Mexicana de Ciencias Agrícolas, 9, 1645-1658.

Fox, J. y G. Rivera (2005). Indígenas migrantes mexicanos en los Estados Unidos. San Diego: Centro de Estudios México-Estados Unidos/Centro de Estudios Comparativos sobre InmigraciónUniversidad de California en San Diego.

Garduño, M., C. Guzmán y L. Zizumbo (2009). “Turismo rural: Participación de las comunidades y programas federales”. El Periplo Sustentable, 17, 5-30.

Gómez, J. (2000). "Los invisibles. Hijos de migrantes en cardonal, Hidalgo". Tesis para obtener el título de maestro en Estudios de Población. Pachuca: Instituto de Ciencias Sociales y Humanidades-Universidad Autónoma del Estado de Hidalgo.

Lozano, F. (2002). "La migración mexicana, su historia e impacto”. Capítulos, 65, mayo-agosto, 146-167. 
Maldonado, C. (2005). Pautas metodológicas para el análisis de experiencias de turismo comunitario. Ginebra: Oficina Internacional del Trabajo (Documento de Trabajo, 73).

Molina, I. (1998). "La polarización del desarrollo global”, Sociedad Civil: Análisis y Debates, II (2), 155-205.

Mollinedo, S. (2008). La incidencia del empleo rural no agrícola y la educación para el trabajo en el proceso de desarrollo rural guatemalteco. Guatemala: Dirección General de Investigación-Universidad de San Carlos de Guatemala.

Monterroso, N. y L. Zizumbo (2008). "La reconfiguración neoliberal de los ámbitos rurales a partir del turismo: ¿Avance o retroceso?” Convergencia. Revista de Ciencias Sociales, 16 (50), 133-164.

Monzón, J.L. (1998). "La economía social: tercer sector de un nuevo escenario”, en M. Vuotto (comp.) (2014). Economía social. Precisiones conceptuales y algunas experiencias históricas. Buenos Aires: Universidad Nacional de General Sarmiento/Altamira/ Fundación Osde (Lecturas sobre la Economía Social, 6), 29-33.

Pérez Aguilar, A. (2008). Diagnóstico Situacional de Salud 2008. Ixmiquilpan: Colegio de Estudios Científicos y Tecnológicos del Estado de Hidalgo.

Rico González, M. (2005) "El turismo como nueva fuente de ingresos para el medio rural de Castilla y León”. Cuadernos de Turismo, 16, 175-196.

Rivera-Salgado, G. (1999). "Mixtec Activism in Oaxacalifornia: Transborder Grassroots Political Strategies”. American Behavioral Scientist, 42, junio-julio, 1439-1458.

Sedesol (2010a). Informe anual sobre la situación de pobreza y rezago social. Ixmiquilpan Hidalgo [en línea]. Subsecretaría de Prospectiva, Planeación y Evaluación-Secretaría de Desarrollo Social/Consejo Nacional de Evaluación de la Política de Desarrollo Social. Disponible en: http://www.sedesol.gob.mx/work/models/SEDESOL/Informes_pobreza/2014/Municipios/Hidalgo/ Hidalgo_030.pdf [2015, 22 de febrero].

(2010b). Catálogo de localidades. Sistema de Apoyo para la Planeación del PDZP. Unidad de Microrregiones-Dirección General 
Adjunta de Planeación Microrregional-Secretaría de Desarrollo Social.

Serrano Avilés, T. (2006). Migración internacional y pobreza en el Estado de Hidalgo. Pachuca: Universidad Autónoma del Estado de Hidalgo.

Tuirán, R. (coord.) (2000). Migración México-Estados Unidos. Presente y futuro. México: Consejo Nacional de Población.

Velasco, L. (1999). "Comunidades transnacionales y conciencia étnica: indígenas migrantes en la frontera México-Estados Unidos”. Tesis de doctorado en Ciencias Sociales con especialidad en Sociología. México: Centro de Estudios Sociológicos-El Colegio de México.

Vogel, M.L. et al. (2004). "Turismo rural modalidad agroturismo: una alternativa de desarrollo para la zona norte de la provincia de Neuquen”. Anuario de Estudios en Turismo, 4 (3), 83-107.

Zizumbo Villarreal, L. (2007), “Turismo en comunidades rurales. Práctica social y estrategia económica”. Tesis doctoral. México: Facultad de Ciencias Políticas y Sociales de la Universidad Nacional Autónoma de México. 
